\title{
Kinetic Analysis of Thermal and Hydrolytic Decomposition of Spiroborate Ester of Curcumin with Salicylic Acid
}

\author{
JEENA JOHN, SUDHA DEVI RUGMINI and BALACHANDRAN SREEDHARAN NAIR* \\ Department of Chemistry, Mahatma Gandhi College, University of Kerala, \\ Thiruvananthapuram, India. \\ *Corresponding author E-mail: sbcnair@gmail.com \\ http://dx.doi.org/10.13005/ojc/330234
}

(Received: March 06, 2017; Accepted: April 14, 2017)

\begin{abstract}
Spiroborate ester of curcumin with salicylic acid (CBS) has been synthesized and characterized by different spectral techniques. The non-isothermal thermogravimetric method was used to study the thermal decomposition of $\mathrm{CBS}$ at the heating rate of $10^{\circ} \mathrm{C} \mathrm{min}{ }^{-1}$ in nitrogen atmosphere. Hydrolytic stability was studied in aqueous acetone system with different percentages of water and temperature. The activation energies associated with the hydrolysis were evaluated using Arrhenius equation and the corresponding values of thermodynamic parameters were determined using Eyring equation. The possible mechanistic route for the hydrolysis of the complex was proposed.
\end{abstract}

Keywords: Curcumin, Boric acid, Salicylic acid, Hydrolytic stability, Thermal stability.

\section{INTRODUCTION}

Curcuma longa commonly called as turmeric is a widely used spice, food coloring agent and preservative agent in Asian countries. ${ }^{1}$ Curcumin is the bioactive component present in turmeric and has many biological applications. ${ }^{2}$ The biological applications include anticarcinogenic, ${ }^{3}$ antioxidant, ${ }^{4-6}$ anti-inflammatory, ${ }^{7}$ anti-HIV, ${ }^{8}$ antimicrobial, ${ }^{9-10}$ anti-viral activity, ${ }^{10}$ etc. Various analogues and derivatives of curcumin have been developed to increase the bioavailability and pharmacological activities of curcumin. ${ }^{11-14}$ Among the prepared derivatives of curcumin, spiroborate ester of curcumin is an important class of compounds widely used for detecting boron in various matrices in different fields like nuclear energy, metallurgy, pharmacy and agriculture..$^{15-16}$ spiroborate ester of curcumin also finds application in diverse fields including material and medicinal sciences. ${ }^{17-18}$

Salicylic acid is a phenolic compound present in fruits, vegetables and spices known for its anti-inflammatory and antioxidant activity. It is the main ingredient in many skin care products. ${ }^{19}$ Curcumin is also used in skin care products 
because of its capability of preventing skin tumors and insults such as spots and wrinkles. ${ }^{20}$ Boron is a non-toxic, non-active and pollution free element and has many applications in the field of anticorrosion, sterilization, anti-wear and flame retardant. Commonly boric acid is used as a chemical food preservative in meat and dairy product because of its ability to inhibit the growth of microorganism. However some reports indicated that boric acid is harmful to human health if consumed in higher amount. ${ }^{21}$

Curcumin forms boron complex with salicylic acid (Scheme 1). The combination of these three biologically important compounds might be result in the formation of a compound having better biological activities. The hydrolysis and thermal stability data of this compound is necessary for the proper interpretation of its application in various fields like material and medicinal sciences. In the present study, synthesis and characterization of spiroborate ester of curcumin with salicylic acid (CBS) were discussed along with its thermal and hydrolytic stability.

\section{MATERIALS AND METHODS}

\section{Chemicals}

All chemicals and solvents were of analytical grade quality and commercially available. The commercial sample of curcumin purchased from Merck Chemie Pvt. Ltd. Mumbai was further purified by column chromatography to get pure curcumin free from its derivatives. ${ }^{22}$

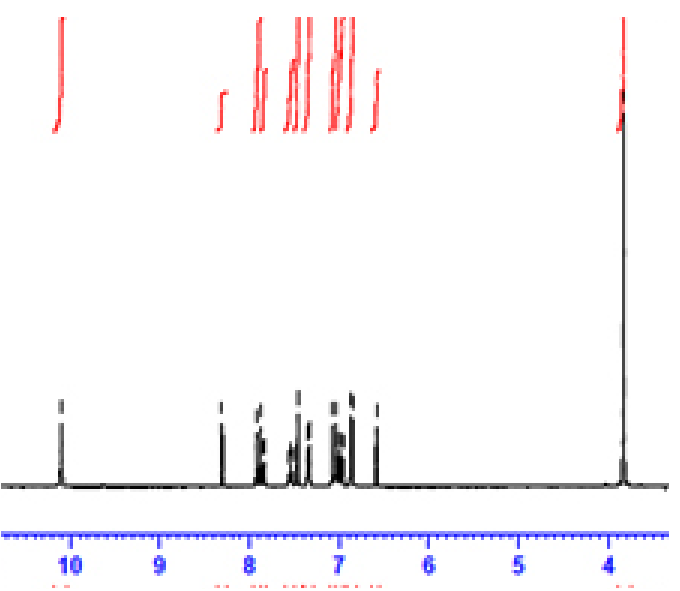

\section{Measurements}

UV spectra were recorded on Elico 198 Biospectrophotometer fitted with a quartz cuvette of $1 \mathrm{~cm}$ path length within the range of $400-700 \mathrm{~nm}$. IR spectra were obtained in $\mathrm{KBr}$ pellet on Perkin Elmer IR spectrophotometer (4000-400 $\left.\mathrm{cm}^{-1}\right) .{ }^{1} \mathrm{H}$ NMR and ${ }^{13} \mathrm{C}$ NMR was recorded in DMSO- $\mathrm{d}_{6}$ solvent on Bruker Avance NMR spectrometer operating at $400 \mathrm{MHz}$. Chemical shifts was quoted in $\delta$ and were related to that of solvents. ${ }^{11} \mathrm{~B}$ NMR was recorded in $50 \%$ acetone-water system on Bruker Avance NMR spectrometer operating at $400 \mathrm{MHz}$ using borax glass as reference. Thermogravimetric analyses were recorded on Perkin-Elmer Thermogravimetric Analyzer in nitrogen atmosphere at a heating rate of $10{ }^{\circ} \mathrm{C} / \mathrm{min}$ from room temperature to $700^{\circ} \mathrm{C}$.

\section{Preparation of CBS}

A mixture of curcumin $(0.01 \mathrm{M})$, boric acid $(0.01 \mathrm{M})$ and salicylic acid $(0.01 \mathrm{M})$ in $10 \mathrm{~mL}$ toluene were heated under reflux using a dean stark trap for $16 \mathrm{hrs}$. The reaction was monitored through TLC and after the completion of the reaction the solvent was removed through filtration to get the solid product. It was further washed with toluene to remove unreacted curcumin (Scheme 1). The structure of the compound was confirmed by different spectral techniques. The ${ }^{1} \mathrm{H}$ NMR and ${ }^{13} \mathrm{C}$ NMR spectrum of CBS are given in Figure 1.

\section{Spectral data of CBS}

Yield 83\%; UV $\lambda \max =508 \mathrm{~nm}$ (acetonitrile); IR $(\mathrm{KBr}): 3449(\mathrm{OH}), 1686(\mathrm{C}=\mathrm{O}$ in lactone ring),

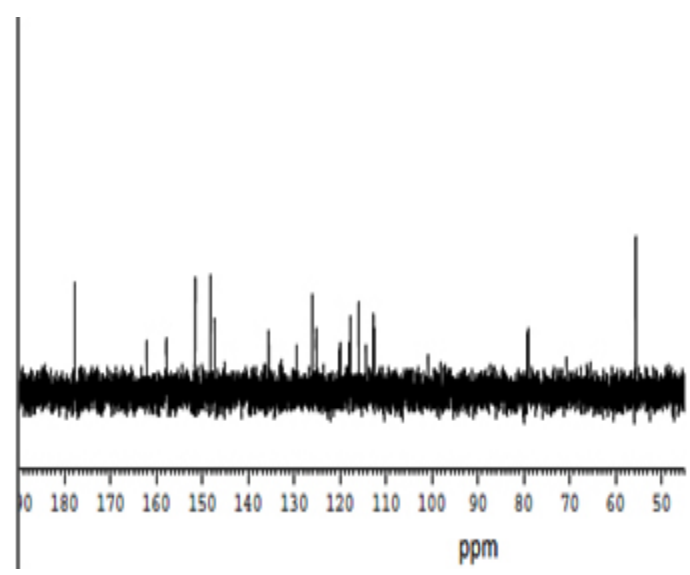

Fig. 1: ${ }^{1} \mathrm{H}$ NMR and ${ }^{13} \mathrm{C}$ NMR spectrum of CBS 
1524 ( $\mathrm{C}=\mathrm{O}$ in curcumin), 1287 (C-O in phenol), 1066 $\mathrm{cm}^{-1}\left(\mathrm{C}-\mathrm{O}\right.$ in $\left.\mathrm{OCH}_{3}\right) ;{ }^{1} \mathrm{H}$ NMR (400 MHz, DMSO-d $)$; $\delta 3.83\left(\mathrm{~s}, 6 \mathrm{H}, \mathrm{OCH}_{3}\right), 6.58(\mathrm{~s}, 1 \mathrm{H}, \mathrm{CH}), 6.85(\mathrm{~d}, \mathrm{~J}=$ $8.4 \mathrm{~Hz}, 2 \mathrm{H}, \mathrm{Ar}-\mathrm{H}), 7.33$ (d, J = 10Hz, $2 \mathrm{H}, \mathrm{Ar}-\mathrm{H}), 7.88$ $(\mathrm{d}, \mathrm{J}=15.6 \mathrm{~Hz}, 2 \mathrm{H},=\mathrm{CH}), 7.03(\mathrm{~d}, \mathrm{~J}=15.6 \mathrm{~Hz}, 2 \mathrm{H}$, $=\mathrm{CH}), 6.96-7.85(\mathrm{~m}, 4 \mathrm{H}, \mathrm{Ar}), 7.46(\mathrm{~s}, 2 \mathrm{H}, \mathrm{Ar}-\mathrm{H})$, 10.09 (s, $2 \mathrm{H}, \mathrm{OH}$ ); ${ }^{13} \mathrm{C}$ NMR: $\delta 55.73,100.60,112.64$, $114.39,115.94,117.76,117.98,120.04,125.23$, $125.99,132.24,135.48,147.31,148.13,151.47$, $157.87,162.12,177.76$.

Hydrolytic stability studies of CBS in aqueous acetone

The kinetics of hydrolysis of CBS was studied spectrophotometrically in acetone water systems using a thermostated Elico 198 Biospectrophotometer. The kinetic runs were carried out at different percentages of acetone - water system ranging from $20 \%$ to $60 \%(\mathrm{v} / \mathrm{v})$ at $510 \mathrm{~nm}$. All reactions were carried out under pseudo first order condition at $50^{\circ} \mathrm{C}$. At room temperature the reaction is slow thus $50{ }^{\circ} \mathrm{C}$ is selected for the hydrolysis studies. The observed first order rate constants were obtained from the slope of logarithmic concentrations of complex versus time graph.

Temperature effect on rate of hydrolysis was investigated by carrying out the hydrolysis reaction at five different temperatures ranging from 40 to $60{ }^{\circ} \mathrm{C}$. Arrhenius equation was used to calculate the activation energy and frequency factor for hydrolysis. ${ }^{23}$ To calculate thermodynamic activation parameters such as enthalpy of activation and entropy of activation, Eyring equation (Eqn. 1) was used, ${ }^{24}$

$$
\ln (k / T)=\left\lfloor\ln \left(\frac{k_{B}}{h_{p}}\right)+\frac{\Delta S^{\ddagger}}{R}\right\rfloor-\frac{\Delta H^{\ddagger}}{R}(1 / T)
$$

Eyring plot were drawn using $\ln (\mathrm{k} / \mathrm{T})$ vs. $1 / T$ and from slope and intercept of this straight line plot, $\Delta \mathrm{H}^{*}$ and $\Delta \mathrm{S}^{\#}$ was calculated. Free energy of activation were calculated using the equation $\Delta \mathrm{G}^{*}$ $=\Delta \mathrm{H}^{\#}-\mathrm{T} \Delta \mathrm{S}^{\#} \cdot .^{25}$

\section{Data analysis}

Data analysis was performed using Microsoft Office Excel worksheet. The goodness of the fit was tested using the correlation coefficient and standard deviation.

\section{RESULTS AND DISCUSSIONS}

\section{Thermal decomposition of CBS}

Thermogravimetric analysis for CBS was carried out from room temperature to $700{ }^{\circ} \mathrm{C}$ and the obtained TG-DTG curve is presented in Figure 2. The thermal decomposition of CBS proceeded with two distinct stages of decomposition. The first stage observed within the temperature range 125-180 ${ }^{\circ} \mathrm{C}$ corresponds to the elimination of two molecules of crystal water attached to CBS

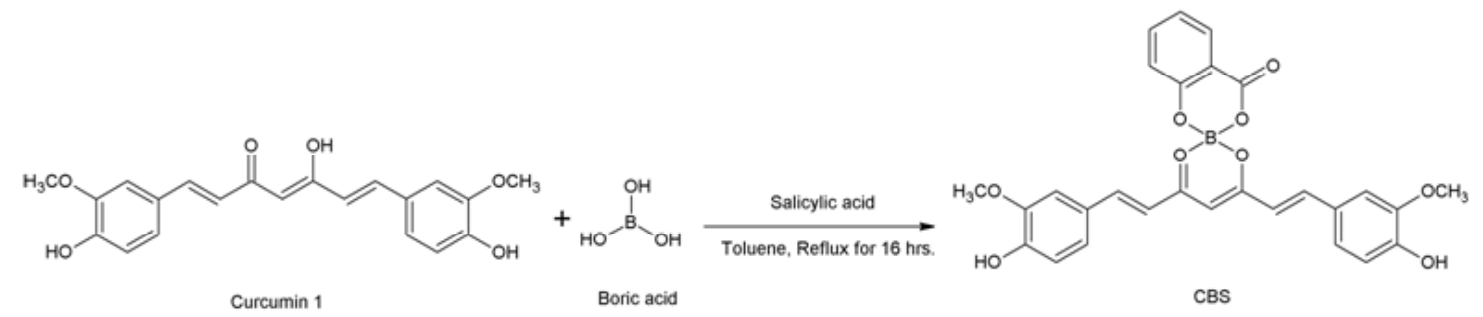

Scheme 1: Synthesis of CBS

Table 1: Thermogravimetric data of CBS

\begin{tabular}{cccccc}
\hline Stages & $\begin{array}{c}\text { Temperature } \\
\text { Range }\left({ }^{\circ} \mathbf{C}\right)\end{array}$ & $\begin{array}{c}\text { Ts } \\
\left({ }^{\circ} \mathrm{C}\right)\end{array}$ & $\begin{array}{c}\text { Weight } \\
\text { loss } \\
\text { Calculated }\end{array}$ & $\begin{array}{c}(\%) \\
\text { Found }\end{array}$ & $\begin{array}{c}\text { Decomposed } \\
\text { fragment }\end{array}$ \\
\hline 1 & $125-180$ & 151 & 7.05 & 7.00 & $2 \mathrm{H}_{2} \mathrm{O}$ \\
2 & $180-330$ & 256 & 23.54 & 23.43 & $\mathrm{C}_{6} \mathrm{H}_{5}-\mathrm{CO}-\mathrm{O}$ \\
\hline
\end{tabular}


with a mass loss of 7.05/7.00 \% (calcd. /found). The second stage is observed at the temperature range $180-330{ }^{\circ} \mathrm{C}$, analogues to the loss of $\mathrm{C}_{6} \mathrm{H}_{5}-$ CO-O group with a mass loss of 23.54/23.43 \% (calcd. /found). These steps follow a continuous weight loss from $310-700^{\circ} \mathrm{C}$ due to the degradation of curcumin moiety. The pattern of decomposition is similar to that reported for bis-salicylatoborate of magnesium. ${ }^{26}$ The thermal degradation data is summarized in Table 1.

\section{Kinetic aspects of thermal degradation}

The kinetics of the thermal decomposition of CBS was studied by non-isoconversional method. The activation energy (Ea) and pre-exponential factor (A) were calculated using six methods given in Table

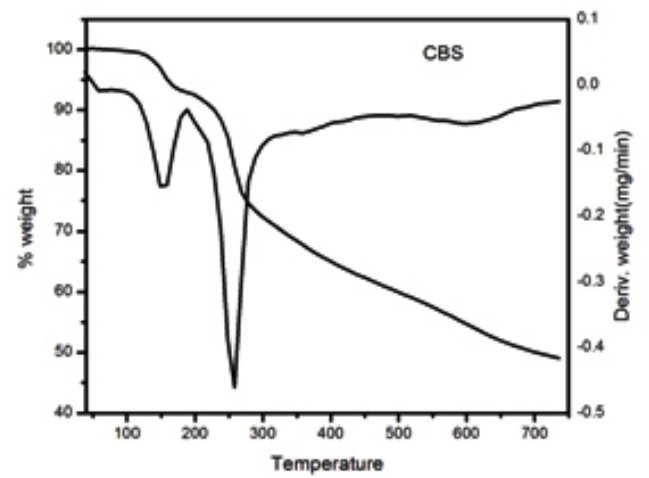

Fig. 2: TG and DTG curves of CBS in nitrogen atmosphere at a heating rate of $10^{\circ} \mathrm{C} \mathrm{min}^{-1}$.

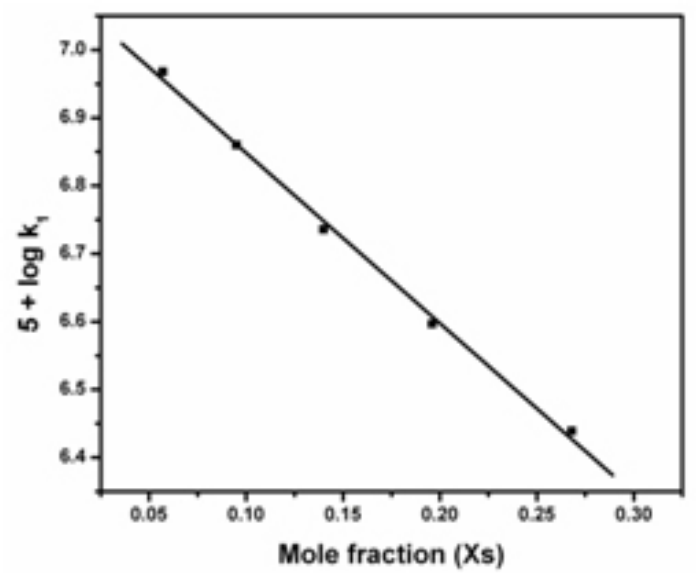

Fig. 3: Variation of first order rate constant for the hydrolysis of CBS with mole fraction of the reaction medium. (Slope: $-2.5097 \mathrm{~s}^{-1}, \mathrm{SD}$ : 0.0136, $R^{2}: 0.9984$ )
$2^{27-32}$. The kinetic parameters were determined from the slope and intercept of the straight line plot of each method mentioned in Table 2.

Linear plots with high correlation coefficient (0.9803-0.9982) were obtained for all methods which indicate that the decomposition is first order in two stages and there is a reasonable agreement between the experimental data and obtained kinetic parameters. ${ }^{33}$ Thethermo gravimetric parameters evaluated graphically using six different nonisothermal methods are listed in Table 3. The parameters calculated using all six methods are comparable and are in agreement with each other. For both decomposition steps, very close positive Ea values were observed, the second stage has higher Ea value than first decomposition step. The high Ea values indicate high thermal stability of CBS. The endothermic nature of thermal degradation was indicated by the positive value of enthalpy of activation energy. The positive values of entropy indicate the less ordered activated state and positive $\Delta G^{\#}$ values indicate the non-spontaneity of thermal degradation.

\section{Hydrolytic stability studies of CBS}

CBS stored in dry organic solvents like acetone, acetonitrile, DMSO, dioxane, etc. showed no change in its $\lambda_{\max }$ value during the storage for three months in room temperature indicating its high solution state stability. Reduction in $\lambda_{\max }$ value was observed during the addition of water. A systematic study was done in order to find the effect of water and temperature on the hydrolytic stability of CBS.

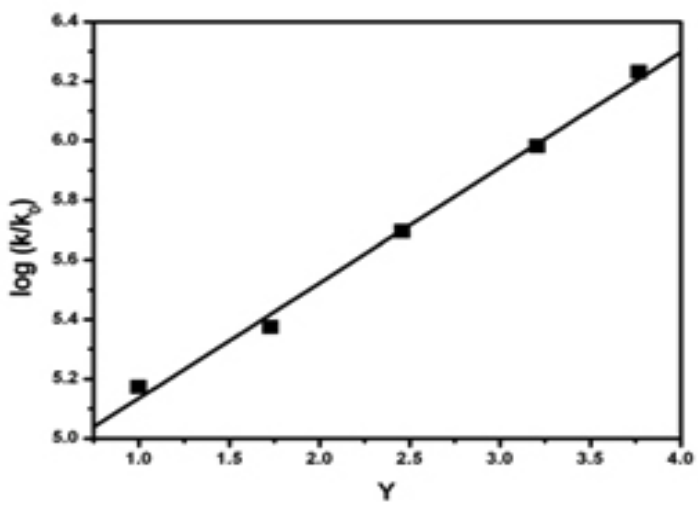

Fig. 4: Grunwald-Winstein plot for the hydrolysis of CBS (Slope: 0.3871, SD: 0.0363 , $R^{2}=0.9973$ ) 

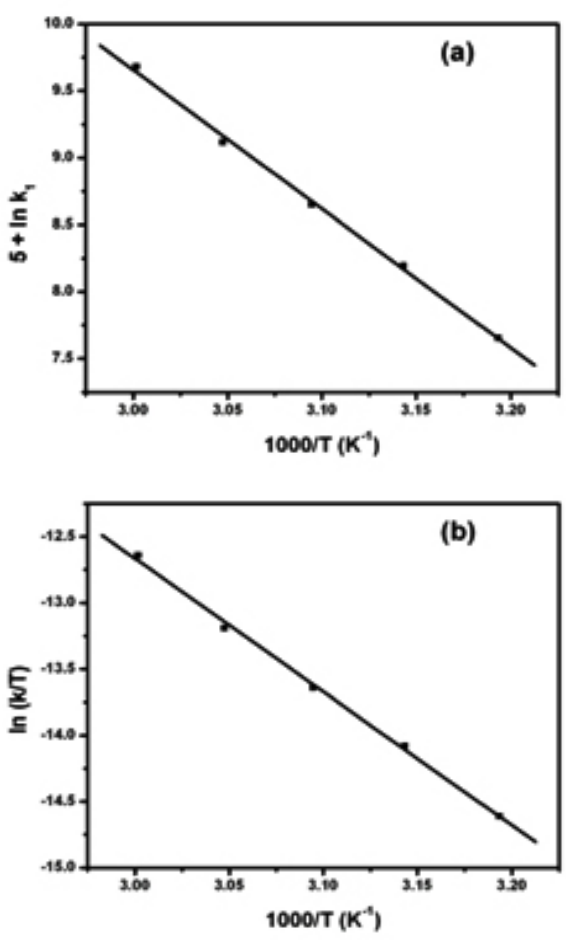

Fig. 5: (a) Arrhenius plot and (b) Eyring plot for the hydrolysis of CBS at different temperatures.

\section{Effect of water}

The hydrolytic decomposition of CBS follows first order kinetics with complete decomposition as shown by zero absorbance for infinity absorbance measurement for every kinetic run. Hydrolysis of CBS was carried out at $50^{\circ} \mathrm{C}$ in different percentages of acetone-water mixtures. The first order rate constants obtained are summarized in Table 4. The results show that the rate constant $\mathrm{k}_{1}$ increases with increase in the water percentage of reaction medium. The mole fraction versus rate constant plot is shown in Figure 3. A linear plot with a correlation coefficient $\left(R^{2}\right) 0.9984$ with a negative slop indicate the rate of reaction is directly proportional to the concentration of water in the reaction medium and the reaction proceed by a simple mechanistic path.

The Grunwald-Winstein plot were drawn using $\log (\mathrm{k} / \mathrm{ko})$ against solvent ionizing power scale, $\mathrm{Y}$ as shown in Figure 4 $^{34-35}$. The $\mathrm{m}$ value obtained from the slope of the GW plot for the hydrolysis of CBS is 0.3871 , which indicates that the intermediate formed during the hydrolysis is chargeless ${ }^{36}$.

\section{Effect of temperature}

The influence of the temperature on the hydrolysis rate constant of CBS was determined

Table 2: Different methods used for the kinetic analysis of thermal degradation of CBS.

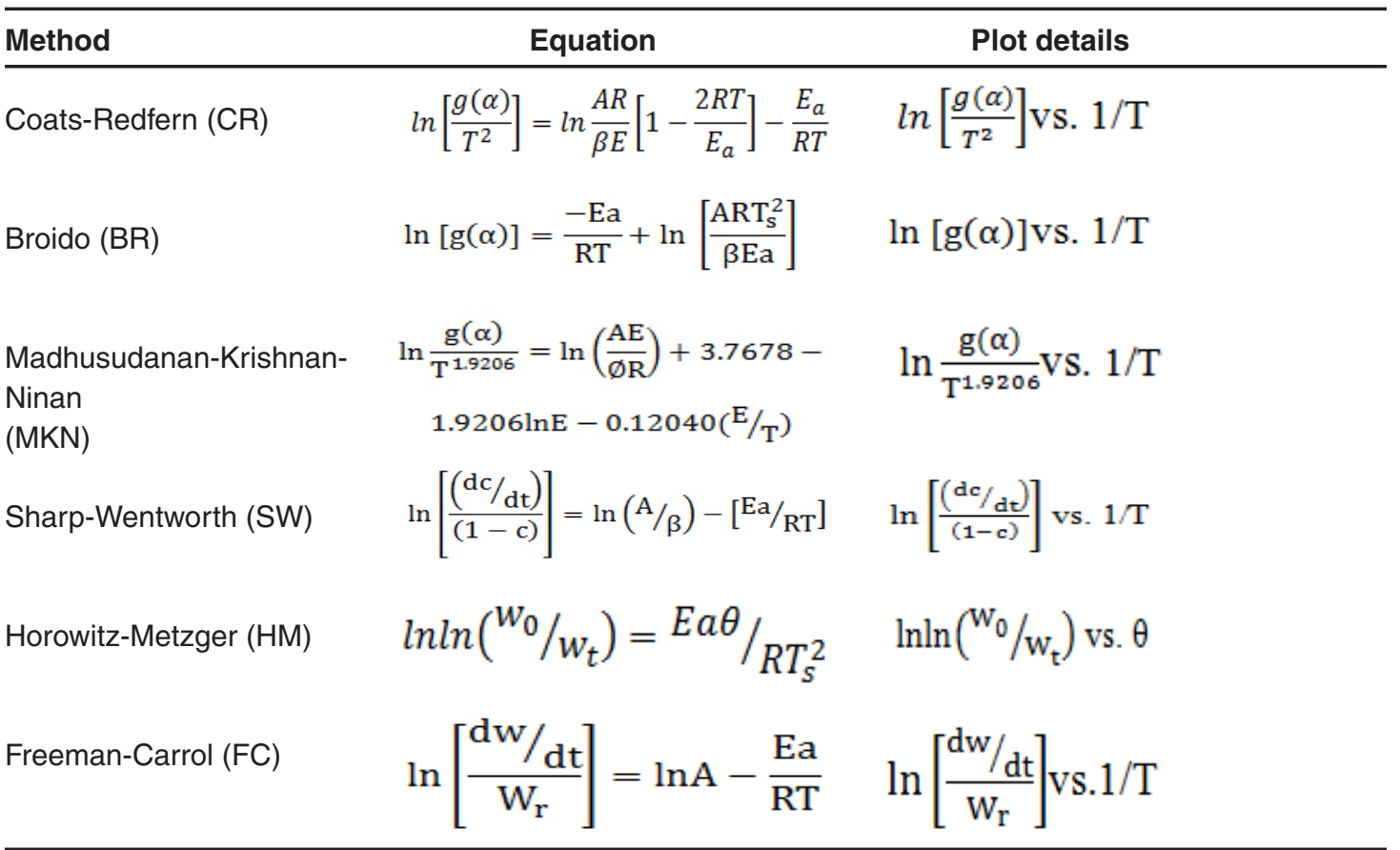


over the temperature range 40 to $60{ }^{\circ} \mathrm{C}$ in $50 \%(\mathrm{v} / \mathrm{v})$ acetone water system and the kinetic parameters at standard temperature $298 \mathrm{~K}$ are presented in Table 5 along with the measured first order rate constants. Arrhenius plot showed a linear relationship between In $\mathrm{k}$ and reciprocal of absolute temperature with correlation coefficient 0.9972 and standard deviation (SD) 0.0653 as shown in Figure 5a. The Eyring plot (Figure 5b) also showed a linear relationship with standard deviation 0.0420 and correlation 0.9988 .

The higher value of enthalpy of transition state indicates that the energy requirement for the formation of intermediate during the hydrolysis of

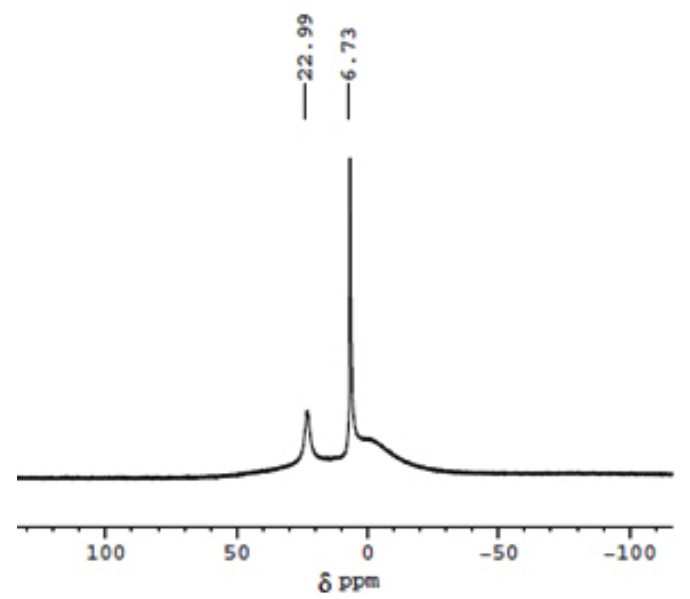

Fig. 6:11B NMR spectrum of CBS recorded during its hydrolysis in $\mathbf{5 0 \%}$ acetone water system at room temperature.
CBS is high. Negative value of $\Delta S^{\#}$ indicates that activated complex is more ordered than the reactant and no significant change occurs in the internal structure of CBS during the formation of activated complex. The $\Delta G^{\#}$ value is positive which indicates the hydrolysis reaction as a thermodynamically feasible reaction. Thus the kinetic parameters indicate the possibility of a bulky transition state during hydrolysis ${ }^{36}$.

\section{Mechanism for the hydrolysis of CBS}

UV-Visible, ${ }^{11} \mathrm{~B}$ NMR spectral studies and HPLC analysis were used to study the product formed during the hydrolysis of CBS. The UV-visible spectra of CBS recorded during the hydrolysis shows a decreasing peak at 510 and an increasing peak at $420 \mathrm{~nm}$. The peak at 420 is due to the formation of curcumin as one of the hydrolysis product. ${ }^{37}$ Figure 6 is the ${ }^{11} \mathrm{~B}$ NMR spectrum of CBS recorded at room temperature, three hours after the hydrolysis has begun. The spectrum shows that solution contains two different boron species. The peak at 6.73 corresponds to tetrahedral boron atom present in CBS. The trigonal boron atom present in boric acid gives a signal at $\delta \sim 19^{38}$ which is not observed in this case. An additional signal observed at $\delta 22.99$ can be ascribed to tetrahedral boron $\left[\mathrm{B}(\mathrm{OH})_{4}^{-}\right]$, as one of the hydrolysis product. The product analysis by HPLC in methanol medium confirms the presence of curcumin and salicylic acid as hydrolysis product.

The formation of bis-chelate boron salicylic acid complex was reported to takes place by a

Table 3: Thermodynamic data of the thermal decomposition of CBS.

\begin{tabular}{|c|c|c|c|c|c|c|c|}
\hline Stage & Method & $\mathbf{R}^{2}$ & $\begin{array}{c}\mathrm{Ea} \\
\left(\mathrm{kJ} \mathrm{mol}^{-1}\right)\end{array}$ & $A\left(s^{-1}\right)$ & $\begin{array}{c}\Delta \mathbf{H}^{\#} \\
\left(\mathrm{~kJ} \mathrm{~mol}^{-1}\right)\end{array}$ & $\begin{array}{c}\Delta \mathbf{S}^{\#} \\
\left(\mathbf{J ~ K}^{-1} \mathrm{~mol}^{-1}\right)\end{array}$ & 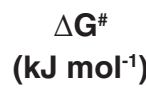 \\
\hline \multirow[t]{6}{*}{1} & CR & 0.9951 & 173.30 & $5.13 \times 10^{19}$ & 169.77 & 121.16 & 118.31 \\
\hline & BR & 0.9955 & 178.75 & $1.52 \times 10^{22}$ & 175.22 & 168.47 & 103.67 \\
\hline & MKN & 0.9951 & 173.41 & $2.18 \times 10^{22}$ & 169.00 & 169.64 & 97.04 \\
\hline & SW & 0.9803 & 174.33 & $8.25 \times 10^{17}$ & 169.93 & 84.99 & 124.88 \\
\hline & $\mathrm{HM}$ & 0.9979 & 179.57 & $2.43 \times 10^{20}$ & 174.84 & 131.65 & 99.93 \\
\hline & $\mathrm{FC}$ & 0.9816 & 174.33 & $1.67 \times 10^{17}$ & 169.42 & 70.83 & 127.64 \\
\hline \multirow[t]{6}{*}{2} & CR & 0.9928 & 225.44 & $2.49 \times 10^{20}$ & 221.04 & 132.46 & 150.83 \\
\hline & BR & 0.9982 & 224.47 & $1.78 \times 10^{21}$ & 220.06 & 148.83 & 141.18 \\
\hline & MKN & 0.9974 & 215.91 & $1.53 \times 10^{21}$ & 211.50 & 147.58 & 133.29 \\
\hline & SW & 0.9817 & 214.71 & $2.29 \times 10^{23}$ & 210.30 & 189.20 & 110.02 \\
\hline & $\mathrm{HM}$ & 0.9979 & 226.27 & $3.23 \times 10^{20}$ & 221.54 & 134.04 & 145.27 \\
\hline & $\mathrm{FC}$ & 0.9896 & 214.71 & $1.35 \times 10^{21}$ & 210.30 & 146.54 & 132.63 \\
\hline
\end{tabular}


two-step mechanism, where the mono-chelate complex was formed in the first stage followed by the condensation reaction with fully protonated salicylic acid to form bis-chelate complex. ${ }^{39}$ The condensation takes place by the transfer of one of the hydrogen

Table 4: First order rate constant for the hydrolysis of CBS in different \% of acetone water medium at $50{ }^{\circ} \mathrm{C}$.

\begin{tabular}{lcc}
\hline $\mathbf{V}(\%)$ acetone & $\begin{array}{c}\text { Mole fraction } \\
\text { of acetone }\end{array}$ & $\begin{array}{c}\text { Rate } \\
\text { constant } \\
\mathbf{1 0 ^ { 4 }} \mathbf{k}_{\mathbf{1}}\left(\mathbf{s}^{-1}\right)\end{array}$ \\
\hline 20 & 0.057 & $9.30 \pm 0.03$ \\
30 & 0.095 & $7.25 \pm 0.04$ \\
40 & 0.140 & $5.45 \pm 0.01$ \\
50 & 0.196 & $3.95 \pm 0.03$ \\
60 & 0.268 & $3.23 \pm 0.02$ \\
\hline
\end{tabular}

from the ligand to hydroxyl group of boric acid to eliminate as a water molecule.The significance of proton transfer for the complexation reaction of boric acid is demonstrated by the early work of Pizer and co-workers. ${ }^{40-41}$ For the reverse process, the hydrolysis of bis-chelate, the addition of water molecule to liberate the fully protonated salicylic acid and mono-chelate boron complex can be suggested followed by the rapid hydrolysis monochelate.

In the hydrolysis reaction the oxygen atom of the entering water molecule interact the central boron as nucleophile, simultaneously the hydrogen form an intermolecular hydrogen bond with the B-O-C oxygen to form a cyclic transition state as shown in Scheme 2. The nucleophilic attack of $-\mathrm{OH}$ group towards boron atom to form a five coordinated transition state in rate determining step has been reported in the hydrolysis of four coordinate boron

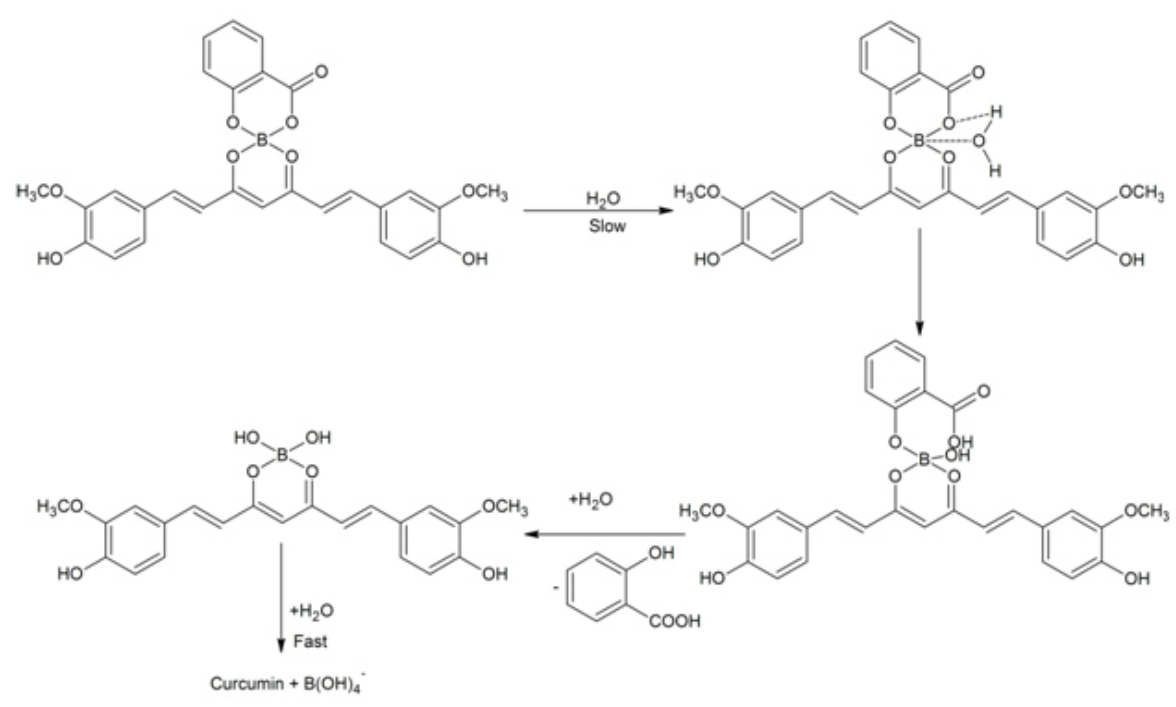

Scheme 2: Plausible mechanism for the hydrolysis of CBS.

Table 5: Kinetic and thermodynamic parameters for the hydrolysis of CBS in $\mathbf{5 0} \%$ acetone water system.

\begin{tabular}{|c|c|c|c|c|c|c|c|}
\hline $\mathrm{T}\left({ }^{\circ} \mathrm{C}\right)$ & $10^{4} k\left(s^{-1}\right)$ & $\begin{array}{c}k \text { at } \\
25^{\circ} \mathrm{C} \\
\left(\mathrm{s}^{-1}\right)\end{array}$ & $\begin{array}{c}\text { Ea } \\
\left(\mathrm{KJ} \mathrm{mol}^{-1}\right)\end{array}$ & $A\left(s^{-1}\right)$ & $\begin{array}{c}\Delta \mathbf{H}^{\#} \\
\left(\mathrm{~kJ} \mathrm{~mol}^{-1}\right)\end{array}$ & $\begin{array}{c}\Delta \mathbf{S}^{\#} \\
\left(\mathrm{~J} \mathrm{~K}^{-1} \mathrm{~mol}^{-1}\right)\end{array}$ & $\begin{array}{r}\Delta \mathrm{G}^{\#} \\
\left(\mathrm{~kJ} \mathrm{~mol}^{-1}\right)\end{array}$ \\
\hline 40 & 1.42 & & & & & & \\
\hline 45 & 2.44 & & & & & & \\
\hline 50 & 3.85 & $2.67 \times 10^{5}$ & 86.33 & $3.21 \times 10^{37}$ & 83.64 & -51.88 & 99.11 \\
\hline 55 & 6.14 & & & & & & \\
\hline 60 & 10.8 & & & & & & \\
\hline
\end{tabular}


complexes. ${ }^{42-43}$ The interaction of water molecule to boron was reported in the complexation of boric acid with catechols and salicylic acid. ${ }^{26,44}$ Shao and co-workers have postulated the formation of five coordinated boron intermediate during the hydrolysis of boric acid complex with chromotropic acid. ${ }^{44}$

The present data is not sufficient to predict the exact nature of the complex formed during hydrolysis. However it can be shown that the B-O-C bond and the $\mathrm{O}-\mathrm{H}$ bond of hydrogen bonded water molecules breaks resulting in the hydrolysis of complex, the further addition of water resulted in the removal of salicylate moiety from the complex. The extended conjugation of curcumin with boron species suggest the removal of salicylate moiety followed by curcumin from the complex. Since the complex possess a highly symmetric structure and the oxygen atom present in $\mu$-oxobridge possess very low electron density the addition of hydrogen atom to the complex is a very slow process. Therefore the rate determining step is the formation of bulky intermediate through hydrogen bonding. ${ }^{44}$ The values of thermodynamic parameters also support the formation of moderately stable complex. The positive value of $\Delta \mathrm{H}^{\#}$ favors the formation of complex and the negative $\Delta S^{\#}$ value indicates the formation of a rigid structure.

CBS has four B-O bonds that are vulnerable to hydrolytic attack. The hydrolysis of CBS begins with the cleavage of two B-O bonds between salicylic acid and boron through the formation hydrogen bond with water which results in the release of salicylic acid along with tetrahedral curcumin boron complex similar to that of boron complex of chromotropic acid. ${ }^{44,11} \mathrm{~B}$ NMR spectrum confirms the absence of trigonal boron in hydrolysis process. The absence of any specific peak in HPLC analysis suggest a very fast second stage process resulting in the formation of curcumin and $\left[\mathrm{B}(\mathrm{OH})_{4}^{-}\right]$.

\section{CONCLUSION}

Spiroborate ester of curcumin with salicylic acid has been synthesized and characterized. Thermal degradation behavior was analyzed by TGDTG technique and kinetic parameters associated with thermal degradation were evaluated using different non-isothermal methods. The values obtained from these methods are comparable and are in good agreement with each other. Hydrolytic stability of the complex was studied spectrophotometrically in acetone water system at different percentage of water and temperature. The reaction followed first order kinetics and hydrolysis rate increased with increase in temperature and percentage of water. Kinetic data obtained from the hydrolysis study indicates the possibility of a bulky intermediate during hydrolysis. UV-Visible, HPLC and ${ }^{11} \mathrm{~B}$ NMR spectral analysis were conducted to analyze the hydrolysis product. Based on that a plausible mechanism for the hydrolysis was suggested.

\section{ACKNOWLEDGEMENT}

The financial support from the Council of Scientific and Industrial Research (Grant No. 08/538/(0003)/2012-EMR-1), New Delhi is gratefully acknowledged. Authors would also like to thank SAIF, Cochin and IISER Thiruvananthapuram for carrying out spectral analysis.

\section{REFERENCES}

1. Chattopadhyay, I.; Biswas, K.; Bandyopadhyay, U.; Banerjee, R. K. Turmeric and curcumin: Biological actions and medicinal applications. Current Science, 2004, 87, 44-53.

2. Gupta, A.P.; Gupta, M.M.; Kumar, S. Simultaneous determination of curcuminoids in curcuma samples using high performance thin layer chromatography. J. Liq.Chrom.\& Rel. Technol. 1999, 22, 1561-69.
3. Soudamini, K.K.; Kuttan, R. Inhibition of chemical carcinogenesis by curcumin. J.Ethnopharmacol. 1989, 27, 227-233.

4. Jayaprakasha, G.K.; Rao, L.J.; Sakariah, K.K. Antioxidant activities of curcumin, demethoxycurcumin and bisdemethoxycurcumin. Food Chem. 2006, 98, 720-724.

5. Khopde, S.M.; Priyadarsini, K.I.; Venkadesan, 
U.P.; Rao, M.N.A. Free radical scavenging ability and antioxidant efficiency of curcumin and its substituted analogue. Biophys. Chem. 1999, 80, 85-91.

6. Elizabeth, K; Rao, M.N.A. Oxygen radical scavenging activity of curcumin. Int. J. Pharm. 1990, 58, 237-240.

7. Nurfina, A.N.; Reksohadiprodjo, M.S.; Timmerman, H.; Jenie, U.A.; Sugiyanto, D.; van der Goot, H. Synthesis of some symmetrical curcumin analogues and their anti-inflammatory activity. Eur. J. Med. Chem. 1997, 32, 321-28.

8. Mazumder, A.; Neamabi, N.; Sunder, S.; Schilz, J.; Pertz, H.; Eich, E.; Pommier, Y. Curcumin analogs with altered potencies against HIV-1 integrase as probes for biochemical mechanisms of drug action. J. Med. Chem. 1997, 40, 3057-3063.

9. Akram, M.; Shahab-Uddin; Ahmed, A.; Usmangghani, K.; Hannan, A.; Mohiuddin, E.; Asif, M. Curcuma longa and curcumin: A review article. J. Biol-Plant Biol. 2010, 55, 65-70.

10. Moghadamtousi, S.Z.; Kadir, H.A.; Hassandarvish, P.; Tajik, H.; Abubakar, S.; Zandi, K. A review on antibacterial antiviral and antifungal activity of curcumin. Biomed. Res. Int. 2014, 2014, 186864-76.

11. Liang, G.; Shao, L.; Wang, Y.; Zhao, C.; Chu, Y.; Xiao, J.; Zhao, Y.; Li, X.; Yang, S. Exploration and synthesis of curcumin analogues with improved structural stability both in vitro and in vivo as cytotoxic agents. Bioinorg.Med.Chem. 2009, 17, 2623-2631.

12. Nugroho, A.E.; Ikawati, Z.; Sardjiman; and Maeyama, K. Effects of benzylidenecyclopentanone analogues of curcumin on histamine release from mast cells. Biol. Pharm. Bull. 2009,32, 842-849.

13. Changtam, C.; Koning, H.P.; Ibrahim, H.; Sajid, M.S.; Gould, M.K.; Suksamrarn, A. Curcuminoid analogs with potent activity against Trypanosoma and Leishmania species Eur.J.Med. Chem. 2010, 45, 941956

14. Somparn, P.; Phisalaphong, C.; Nakornchai, S.; Unchern, S.; Morales, N.P. Comparative antioxidant activities of curcumin and its demethoxy and hydrogenated derivatives Biol.
Pharm. Bull. 2007,30, 74-78.

15. Uppstrom, L.R.; Ostling, G. A modified method for determination of boron with curcumin and a simplified water elimination procedure. Anal. Lett. 1976, 9, 311-324.

16. Dyrssen, D.W.; Uppstrom, L.R.; Novikov, Y.P. Studies on the chemistry of the determination of boron with curcumin. Anal. Chim. Acta, 1972, 60, 139-151.

17. Sui, Z.; Salto, R.; Li, J.; Craik, C.; Ortiz de Montellano, P.R.Inhibition of the HIV-1 and HIV-2 proteases by curcumin and curcumin boron complexes.Bioorg. Med. Chem. 1993, 1,415-422.

18. Ran, C.; Xu, X.; Raymond, S.B.; Ferrara, B.J.; Neal, K.; Bacskai, B.J.; Medarova, Z.; Moore, A. Design, synthesis and testing of difluoroboron-derivatizedcurcumins as near-infrared probes for in-vivo detection of amylode-beta deposits, J. Am. Chem. Soc. 2009, 131, 15257" 15261

19. Randjelovic, P.; Veljkovic, S.; Stojilijkovic, N.; Sokolovic, D.; Ilic, I.; Laketic, D.; Randjelovic, D.; Randjelovic, N. The beneficial biological properties of salicylic acid, Acta facultatis medicae Naissensis. 2015, 32, 259-265.

20. Goncalves, G.M.S.; da Silva, G.H.; Barros, P.P.; Srebernich, S.M.; Shiraishi, C.T.C.; de Camargos, V.R.; Lasca, T.B. Use of Curcuma longa in cosmetics: extraction of curcuminoid pigments, development of formulations, and in vitro skin permeation studies. Braz. J. Pharm. Sci., 2014, 50, 885-893.

21. See, A.S.; Salleh, A.B.; Bakar, F.A.; Yusof, N.A.; Abdulamir A.S.; Heng, L.Y. Risk and health effect of boric acid, Am. J. Appl. Sci.2010, 7, 620-627.

22. Asha, R.; Devi, R.S.; Priya, R.S.;Balachandran, S.; Mohanan, P.V.; Abraham, A. Bioactive derivatives of curcumin attenuate cataract formation in vitro.Chem. Biol. Drug Des. 2012,80, 887.

23. Svirbely, W.J.; Kundell, F.A. The kinetics of competitive-consecutive second-order reactions involvingdifunctional unsymmetrical molecules. The kinetics of the alkaline hydrolysis of diethyl malate J.Am. Chem. Soc. 1967,89, 5354.

24. Al-Ghouti, M.; Khraishehb, M.A.M.; Ahmada, M.N.M.; Allen, S. Thermodynamic behavior 
and the effect of temperature on the removal of dyes from aqueous solution using modied diatomite: A kinetic study.J. Colloid Interface Sci.2005,287, 6.

25. Sismanoglu, T.; Pura, S.Adsorption of aqueous nitrophenols on clinoptilolite. Colloids Surf A: Physicochem. Eng. Asp.2001,180, 1.

26. Kose, D.A.; Zumreoglu-Karan, B.; Hokelek, T. A comparative examination of mono- and bis-chelate salicylatoborate complexes and the crystal structure of layered magnesium bis-salicylatoborate, Inorg.Chim.Acta.2011, 375, 236-241.

27. Coats, A.W.; Redfern, J. P.Kinetic parameters from thermogravimetric data. Nature,1964,201, 67.

28. Broido, A.A.A simple, sensitive graphical method of treating thermogravimetric analysis data. J.Polym. Sci. 1969,2A,1761.

29. Madhusudhanan, P.M.; Krishnan, K.; Ninan, K. N.New approximation for the $p(x)$ functions in the evaluation of non-isothermal kinetic data. Thermochim. Acta, 1986, 97, 189.

30. Sharp, J. B.; Wentworth, S.A. Kinetic analysis of thermogravimetric data.Anal. Chem. 1969,41, 2060.

31. Horowitz, H.H.; Metzger, G. A new analysis of thermogravimetric traces. Anal. Chem. 1963,35, 1465.

32. Freeman, E.S.; Carroll, B. The application of thermoanalytical techniques to reaction kinetics: The thermogravimetricevalution of the kinetics of the decomposition of calcium oxalate monohydrate. J. Phys. Chem.1958,62, 394.

33. Adly, O.M.I.; Taha, A.; Fahmy, S.A. Synthesis, spectral characterization, molecular modeling and antimicrobial activity of new potentially $\mathrm{N}_{2} \mathrm{O}_{2}$ schiff base complexes, J. Mol. Struct. 2013, 1054, 239-250.

34. Winstein, S.; Grunwald, E.; Jones, H.W.The correlation of solvolysis rates and the classification of solvolysis reactions into mechanistic categories.J. Am. Chem. Soc. 1951, 73, 2700.

35. Grunwald, E.; Winstein, S.The Correlation of solvolysisrates.J. Am. Chem. Soc.1948,70, 846.

36. Koh, H.J.; Kang, S.J. Application of the extended Grunwald-Winstein equation to the solvolysis of phenyl methanesulfonyl chloride in aqueous binary mixtures.Bull. Korean Chem. Soc. 2011, 32, 1897.

37. Chignell, C.F.; Bilski, P.; Reszka, K.J.; Motten, A.G.; Sik, R.H.; Dahl, T.A. Spectral and photochemical properties of curcumin, Photochem. Photobiol.1994, 59, 295-302.

38. Kose, D.A.; Karan, B.Z. Mixed-ligand complexes of boric acid with organic biomolecules, Chemical papers, 2012,66, 54-60.

39. Basset, J.; Mathews, P.J. The preparation and properties of some bis(salicylato) borate (III) salts with large cations, J. Inorg. Nucl. Chem.1978, 40, 987-992.

40. Pizer, R.; Babcock, L.Mechanism of the complexation of boron acids with catechol and substitutedcatechols, Inorg. Chem.1977, 16, 1677-1681

41. Friedman, S.; Pizer, R. mechanism of the complexation of phenyl boronic acid with oxalic acid. Reaction which requires ligand donor atom protonation. J. Am. Chem. Soc. 1975,97, 6059-6062.

42. Pepperberg, I.M.; Halgren, T.A.; Lipscomb, W.N. A molecular orbital study of the role of $\mathrm{BH}_{5}$ in the hydrolysis of $\mathrm{BH}_{4}^{-}$. J. Am. Chem. Soc. 1976,98, 3443.

43. Kreevoy, M.M.; Hutchins, J.E.C. $\mathrm{H}_{2} \mathrm{BH}_{3}$ as an intermediate in tetrahydridoborate hydrolysis. J. Am. Chem. Soc.1972, 94, 6371.

44. Shao, C.;Matsuoka, S.;Miyazaki,Y.;Yoshimura, K.;Suzuki, T.M.; Tanaka, D.A.P. Equilibrium and kinetic studies on the complexation of boric acidwith chromotropic acid.J. Chem. Soc. Dalton Trans. 2000,18, 3136. 